\title{
Questions of control of hormone content in fish and other aquatic organisms (metaanalysis)
}

\author{
Olga Bagryantseva ${ }^{1,2}$, Vladimir Skakun. ${ }^{3}$, Ilya Sokolov ${ }^{1}$, and Zinaida Gureu ${ }^{1}$ \\ 1Federal State Budgetary Institution of Science "Federal Research Center for Nutrition, Biotechnology and Food Safety", 2/14, Ustinsky \\ passage, Moscow, 115446, Russia; \\ 2First Moscow State Medical University named after I. M. Sechenov, Ministry of Health of the Russian Federation, 2, building 4, str. \\ Bolshaya Pirogovskaya, Moscow, 119435, Russia \\ 3 Federal State Budgetary Scientific Institution "All-Russian Research Institute of Fisheries and Oceanography", 17A, Krasnoselskaya \\ str., Moscow, 107140, Russia
}

\begin{abstract}
Between 1995 and 2018, the production of fish and fishery products using feed increased from 12 to 54.3 million tons. In the cultivation of such products in many countries, hormones are widely used as growth stimulants to increase the efficiency of feed conversion for the purpose of sex reversal, as well as for artificial reproduction. Hormones, especially their synthetic forms, are poorly metabolized in the marine organisms, which leads to their accumulation in the food matrix. When they enter the human body, they are capable of accumulation in tissues, affect the endocrine system and can cause the development of a number of metabolic disorders. The possibility of a carcinogenic effect of hormones has been proven. The data presented substantiate the need to control the content of hormones in fish and fish products, develop highly sensitive methods for their detection, establish a list of controlled hormones and hormone-like drugs and safety regulations for food products produced with their use. The most sensitive and accurate method in this case is the HPLC-MS/MS method. We believe that for natural (non-synthetic hormones) and synthetic hormones, the criterion for their absence in the sample should be the sensitivity threshold of the used research method (at least $20 \mathrm{ng} / \mathrm{kg}$ ).
\end{abstract}

\section{Introduction}

According to the Food and Agriculture Organization of the United Nations (FAO), global fishing production in 2018 reached 96.4 million tons, up 5.4\% on average over the previous three years. This growth is mainly driven by marine fisheries. Catches in inland waters during this period amounted to 12.0 million tons. At the same time, China produces $15 \%$ of the total volume of seafood, Indonesia - 7\%, Peru - 7\%, India - 6\%, the Russian Federation - 5\%, the United States of America - 5\%, Vietnam - 3\%. The top 20 producing countries accounted for about $74 \%$ of all fishery products [1].

During the period from 1995 to 2015 , the production of aquaculture products using feed increased from 12 to 51 million tons. In 2018, the world production of fish in aquaculture amounted to 54.3 million tons ( 47 million tons - freshwater fish and 7.3 million tons - sea fish), 17.7 million tons - shellfish, 9.4 million tons of crustaceans, algae 32.4 million tons. Since 1991, China has produced more farmed fish food products than all other countries. China's share in global aquaculture production is currently $\sim 57 \%$. Of the 25 million tons of products produced in 2018, grown in aquaculture using feed, silver carps accounted for 8 million tons and aquatic invertebrates - 17 million tons, mainly marine bivalve mollusks [1]. Hormones are widely used in the cultivation of such products in many countries. Often, hormonal drugs, especially their synthetic forms, are poorly metabolized, which leads to their accumulation in the food matrix. When hormones enter the human body, they are capable of accumulation in tissues, affect the endocrine system and can cause the development of a number of metabolic disorders in the body [2]. The possibility of a carcinogenic effect of hormones has been proven. These effects are manifested when the content of hormones in food in nanogram quantities (ng $\left.\mathrm{l}^{-1} / \mathrm{kg}^{-1}\right)$, which complicates their detection [1]. In accordance with the Technical Regulations of the Customs Union "On Food Safety" (TR CU 021/2011), the content of hormones in food products is not allowed. However, to date, there are no methods of analysis, as well as regulations for their safe content of hormones in fish and fish products. The purpose is substantiation of ways to improve the safety requirements for fish and fish products grown in aquaculture and in reservoirs of fishery Materials and methods: Scientific data are obtained by using Pub Med, Web of Science, Google Scholar databases. Legislative and regulatory acts of the Eurasian Economic Union, the Russian Federation (RU), the Codex Alimentarius Commission, the European Union and other countries. Main results are analysis of production volumes of fish and other aquatic organisms in the RU. Based on the available statistical data, an analysis of the volume of fish and seafood production in ponds, cages, lakes and

*orresponding author: Bagryantseva@ion.ru 
other water bodies of the RU was carried out, that is, in conditions in which hormonal agents are currently used to increase the yield of these products. According to these data, there is a constant increase in the production of fish and fish products in the artificial environment. In line with the trend line, the growth in the production of such products will continue (Figure 1).

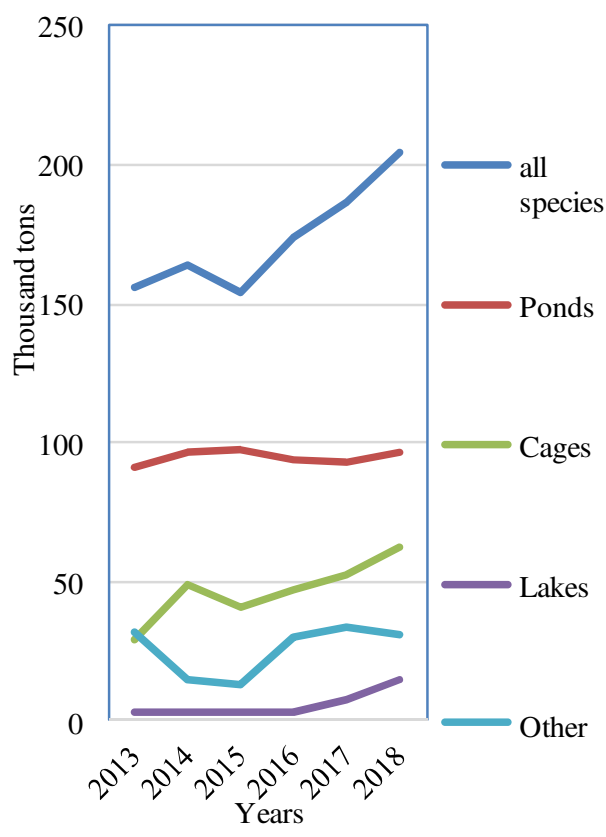

Fig.1. The volume of fish and seafood production in the RU in ponds, cages, lakes and other bodies of water in 2013-2018

It is shown that the largest number of fish products is produced in involuntary conditions: in ponds - $47 \%$, in cages $-31 \%$, in lakes $-7 \%$, others $-15 \%$. At the same time, $93 \%$ of the products produced are fish. The largest production volumes are for carp $(36 \%)$, silver carp $(20 \%)$, trout (19\%) and salmon (11\%) (Figure 2).

The analysis of the data shows that in the Russian Federation the largest volumes of aquaculture production (in ponds and cages) fall to carp (36\%), silver carp (20\%), trout (19\%) and salmon (11\%) [1, 3-5]. The imported amount of fish products in the RU in 2018 amounted to 608398 tons. Of this, the import of frozen fish amounted to 302669 tons, including by countries: Farrere Islands - 110227 tons, Chile - 60389 tons, China - 36168 tons, Greenland - 18787 tons [5].

\section{Results and discussion}

Hormones used in the breeding of fish products

Sex steroid hormones play an important role in many physiological processes, especially in the reproduction of vertebrates. In many teleost fish species, steroid hormones - 17 $\beta$-estradiol (E2), 11-ketotestosterone (11KT) and 17 $\alpha 20 \beta$-dihydroxy-4-pregnen-3-one (DHP) are produced in large quantities in the tissues of the gonads [6]. The level of hormones in the body of fish and fish products depends on the season of the year, temperature, the amount of hormones added to the reservoir with food, population density, the species of fish, the type of hormone [6-10]. The table shows the values of the content of various hormones in the body of carp, depending on the season of the year, grown without the use of hormones (Table 1).

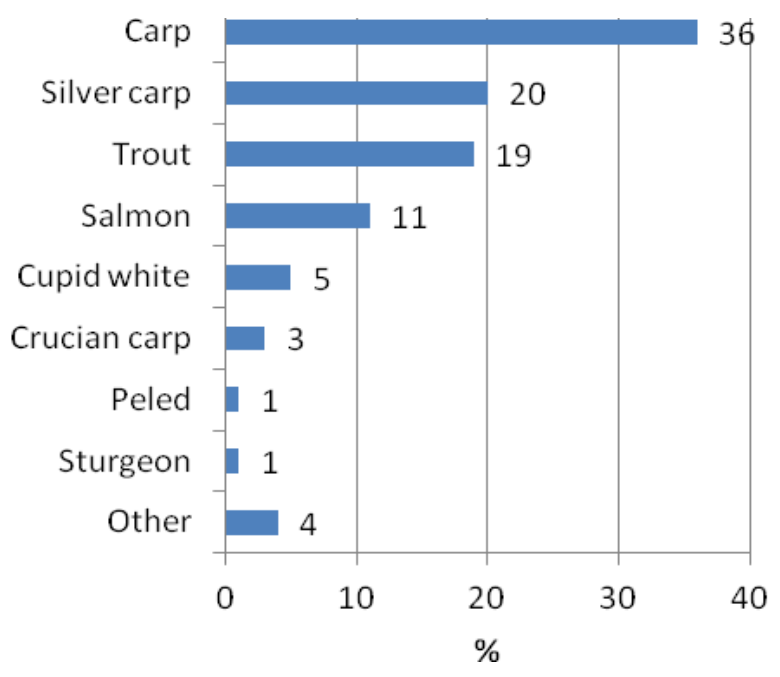

Fig.2. Species composition of fish produced in aquaculture

Table 1. Seasonal changes in the content of hormones in the body of Cyprinus carpio [6]

\begin{tabular}{|c|c|c|c|c|}
\hline \multirow[t]{3}{*}{ Hormone } & \multicolumn{4}{|c|}{ Season of the year } \\
\hline & Winter & Autumn & Summer & Spring \\
\hline & \multicolumn{4}{|c|}{$\mathrm{pg} / \mathrm{ml},(\mathrm{P}>0.05)$} \\
\hline Progesterone & $\begin{array}{ll}0.46 & \pm \\
0.23 & \end{array}$ & $\begin{array}{l}0.62 \quad \pm \\
0.04\end{array}$ & $\begin{array}{ll}0.71 & \pm \\
0.02 & \end{array}$ & $\begin{array}{ll}0.42 & \pm \\
0.01 & \end{array}$ \\
\hline $\begin{array}{l}17-\beta \\
\text { estradiol }\end{array}$ & $\begin{array}{l}30 \pm \\
14.25\end{array}$ & $\begin{array}{l}247.73 \quad \pm \\
134.14\end{array}$ & $\begin{array}{l}110.60 \pm \\
48.27\end{array}$ & $\begin{array}{l}110.43 \\
\pm 80.13\end{array}$ \\
\hline Testosterone & $\begin{array}{ll}0.56 & \pm \\
0.08 & \end{array}$ & $\begin{array}{l}0.71 \\
0.18\end{array}$ & $\begin{array}{ll}0.72 & \pm \\
0.02 & \end{array}$ & $\begin{array}{ll}0.05 & \pm \\
0.0 & \end{array}$ \\
\hline
\end{tabular}

In water, the content of hormones used as pharmaceuticals can be $\mathrm{ng} / \mu \mathrm{g}$ per $1-1$, which is considered non-toxic to humans, but these concentrations can have a negative effect on fish and fish products [2].

Based on studies of the reproductive system of fish and its hormonal regulation in the Russian Federation (and in parallel in Brazil), in the mid-1930s, a method was developed to stimulate the maturation of sex cells in fish and transfer them to a spawning state by injecting a preparation of the pituitary gland of fish. With an increase in the water temperature, the interval of administration of the hormonal drug is reduced from 24 hours at a temperature of $20-22^{\circ} \mathrm{C}$ to $6-8$ hours at a temperature above $27^{\circ} \mathrm{C}$. Accordingly, the dosage of the hormone is also reduced, especially with a preliminary injection of up to $1 / 15-1 / 20$ of the permissive dose 
(permissive dose of $3-5 \mathrm{mg} / \mathrm{kg}$ of the female body weight) [11].

Of interest is the method of obtaining same-sex offspring by artificial reversion (change) of the sex of the producers. The introduction of a male hormone (methyltestosterone) or a female (estradiol) in certain doses when feeding juveniles at the early stages of ontogenesis, corresponding to the onset of differentiation of the gonads, leads to the development of testes in genetic females and the development of a gonad in genetic males according to the female type. Crossbreeding of inverted males with regular females allows you to get same-sex female offspring. Feeding the larvae with food with sex hormones, for example, testosterone, during the first few weeks after hatching increases the yield of males [11-13].

Different types of fish grow better if they are exposed to additional effects of steroid hormones or their analogues. Thus, the introduction of ethylestrenol, methyltestosterone (1 mg per $1 \mathrm{~kg}$ of feed) into the feed helps to accelerate the growth of rainbow trout by 18 $20 \%$, especially when fed with low-protein feed. 17amethyltestosterone supplements (up to $30 \mathrm{mg}$ per $1 \mathrm{~kg}$ of feed) provide the best results in increasing the growth rate of fish for carp, goldfish and tilapia. Anabolic steroids added to feed increase feed digestibility and stimulate protein synthesis [11-13]. The most commonly used hormonal drugs in the cultivation of carp, silver carp, trout and salmon are steroid hormones - 17 $\alpha, 20 \beta$ dihydropreg-4-en-3-one, testosterone, 11-keto testosterone, estrone, 17 $\beta$-estradiol, ethyl estradiol [12].

\section{Hormone Analysis Methods.}

Determination of the residual number of hormones in animal products is challenging due to their low levels that affect the body and the complexity of dietary and biological matrices. However, the development of analytical methods allowing the extraction and concentration of hormones from biological tissues in trace concentrations is necessary since their effect is observed even at $\mathrm{ng} / \mathrm{l}^{-1}$ concentrations. In addition, hormones can be accumulated throughout the entire food chain [14].

Radioimmunoassay (RIA) and enzyme-linked immunosorbent assay (ELISA) are usually extremely sensitive (capable of detecting low pg/ml) [15]. However, the dependence on external calibration and poor reproducibility, the impossibility of reliable quantitative determination of certain types of hormones, as well as cross-reactivity of antibodies in the case of ELISA determine the possibility of using these methods only as screening methods [15-17]. In addition, RIA and ELISA are designed to measure a single hormone, which limits the ability to measure multiple hormones in one sample [12]. Chromatographic methods, including high performance liquid chromatography (HPLC) and gas chromatography (GC) in combination with mass spectrometric analysis (MS), are capable of screening and quantifying analytes [16]. Gas chromatography in combination with mass spectrometry (GC-MS) provides good chromatographic resolution and allows the simultaneous determination of many analytes with a detection limit of $\mathrm{ng} / \mathrm{kg}-1$ or $\mathrm{ng} / \mathrm{l}^{-1}$ [18]. The HPLC method combined with combination mass spectrometry (MS/MS) (HPLC-MS/MS) allows the simultaneous determination of several analytes, while both free and conjugated hormones can be analyzed. This method possesses high specificity, selectivity and sensitivity, and allows achieving low values of quantitative determination $[19,20]$.

However, to date, there are no officially approved methods for the analysis of hormones, as well as levels of the permissible level of their residual amounts in fish and fish products. Due to the greater sensitivity and reproducibility of the HPLC MS/MS method, the researchers of the Federal Research Center for Nutrition and Biotechnology have developed for the first time in the Russian Federation a method for determining the residual amounts of $17 \alpha$, estrone, dihydrotestosterone, 17 - $\alpha$-methyltestosterone, methyldihydrotestosterone in fish. The lower limit for the quantitative determination of hormones using this method is $20 \mathrm{ng} / \mathrm{kg}$. Currently, an application has been filed for a patent of the Russian Federation for an invention - a method for the analysis of hormones in fish and fish products.

\section{Legislation of countries}

In connection with the possible risks of the intake of hormones and hormone-like substances in the human body as part of food products, the Codex Alimentarius Commission established the levels of the maximum allowable content of residual amounts of hormones used as veterinary drugs. For dexamethasone, this is $0.3 \mu \mathrm{g} / \mathrm{l}^{-1}$ in milk, $2 \mu \mathrm{g} / \mathrm{kg}^{-1}$ in the liver and $1 \mu \mathrm{g} / \mathrm{kg}^{-1}$ in meat of cattle, pigs and horses (Acceptable Daily Intake - ADI $0-0.015 \mu \mathrm{g} / \mathrm{kg}^{-1}$ bw per day). For progesterone, testosterone and 17- $\beta$-estradiol, MRLs have not been established, since, in accordance with the conclusion of the Joint FAO/WHO Expert Committee on Food Additives (JECFA), residual amounts of these hormones in food products do not pose a risk to human health, provided that the ADI is not exceeded. For progesterone, the ADI is $0-30 \mu \mathrm{g} / \mathrm{kg}^{-1} \mathrm{bw}$. per day; for testosterone $0-2 \mathrm{mcg} / \mathrm{kg}^{-1}$ bw. per day; for $17-\beta$-estradiol $-0-0.05$ $\mu \mathrm{g} / \mathrm{kg}^{-1}$ bw. per day; for zeranol $-0.5 \mu \mathrm{g} / \mathrm{kg}^{-1}$ bw. per day; for trenbolone $-0-0.02 \mu \mathrm{g} / \mathrm{kg}^{-1}$ bw. per day [21, https://apps.who.int/food-additives-contaminants-jecfadatabase/search.aspx].

Countries such as Canada, Australia, New Zealand, Argentina and the United States allow the use of natural steroid hormones such as testosterone, progesterone and $17 \beta$-estradiol, as well as synthetic hormones such as zeranol and trenbolone acetate. At the same time, only residues of synthetic compounds with maximum residual levels (MRLs) are controlled, since they are considered the most potent endocrine compounds. Brazil has banned the import, production, marketing and use of natural or artificial substances for raising animals and/or increasing weight since 1991. Certain substances (e.g. testosterone, progesterone, estradiol, zeranol, trenbolone acetate), natural or synthetic, are permitted for therapeutic purposes. The Codex Alimentarius Commission (Codex) has determined that hormone residues found in food fro the use of $17 \beta$-estradiol, progesterone and testosterone, 
used in accordance with good manufacturing practices, are not harmful to human health. The use of hormones for the purpose of sex reversal is not regulated by international and national legislation [12,21].

In the European Union, the use of hormones and other anabolic agents for the purpose of fattening, increasing production and stimulating the growth of farm animals is prohibited, and their residues are controlled in food products [22]. At the same time, the use of some hormones is permitted for therapeutic purposes, as well as in the process of animal reproduction. Their use in these cases is allowed on a temporary basis and is carried out under strict veterinary supervision [16]. Legislative acts of China do not provide for the control of the content and the introduction of regulations for the use of hormones and hormone-like drugs in fish and fish products [23].

According to TR CU 021/2011 "On food safety", fish products, grown in aquaculture, as well as caught in water bodies of fishery importance, must undergo the necessary overexposure. The content of hormones and hormone-like substances in fish and other aquatic organisms used for food is not allowed.

However, illegal use of hormones and failure to comply with the withdrawal period can lead to high levels of hormone residues in various animal tissues at levels that could potentially be harmful to the human body. Therefore, it is necessary to control the residual amounts of hormones and hormone-like substances in fish and fish products. We consider it necessary to develop criteria for the culling of fish and fish products in case of detection of hormones in them. Therefore, in the case of detecting hormones in a sample, the fact of detecting any quantities can serve as a justification for refusing to use such food products. We believe that for natural (non-synthetic hormones) and synthetic hormones, the criterion for their absence in the sample should be the sensitivity of the used research method.

\section{CONCLUSION}

The observed increase in the production of fish and fish products in aquaculture, ponds and cages, including with the use of hormones and hormone-like drugs, requires the development of measures to manage the risks of their use. As a result of the analysis of the available data, the necessity to control the content of hormones in fish and fish products, the development and approval of highly sensitive methods for their detection and the establishment of safety regulations for food products produced using hormones and hormonelike drugs are shown. In the case of detection of hormones in a sample, the fact of their detection of any quantities may serve as a justification for refusing to use such food products. We believe that for natural (non-synthetic hormones) and synthetic hormones, the criterion for their absence in the sample should be the sensitivity of the used research method. The most sensitive and 8 accurate method in the case of analyzing fish and fish products for the content of hormones and hormone-like drugs is the HPLCMS/MS method.

\section{ACKNOWLEGEMENTS}

The work was carried out at the expense of subsidies for the implementation of a state task within the framework of the Program of fundamental scientific research (theme of the Ministry of Education and Science of Russia No. 0529-2019-0057).

\section{REFERENCES}

1. The State of World Fisheries and Aquaculture (SOFIA), (Rome, FAO, 2020)

2. Th. H. Miller, N. R. Bury, S. F. Owen Environ Pollut. Aug., 239, 129-146 (2018)

3. Statistical information on the fishing industry in Russia 2013-2014, Federal Agency for Fisheries, (FGBNU "VNIRO", Moscow, 2015).

4. Statistical information on the fishing industry in Russia 2013-2014, Federal Agency for Fisheries, (FGBNU "VNIRO", Moscow 2017).

5. Statistical information on the fishing industry in Russia 2013-2014, Federal Agency for Fisheries, (FGBNU "VNIRO", Moscow, 2019).

6. V. Taghizadeh, M. R. Imanpoor, N. Mehdinejad Springerplus. 30, 2(1), 193, (2013)

7. W. I. Doyle, X. P. Meeks The Journal of Neuroscience, 38(14), 3377-3387, (2018)

8. J. Weidner, C. H. Jensen, J. Giske et al. Biology Open., 9, bio046144, (2020)

9. J. I. Bertucci, A. M. Blanco, L. Sundarrajan, et al. Front. Endocrinol, 10, 83, (2019)

10. V. C. Motaa, C. I. M. Martinsb, E. H. Edinga Aquacultural engineering 62, 9-16 (2014)

11. Yu. A.Privezentsev, V. A. Vlasov Fish farming. (Moscow, 2004)

12. C. A. Hoga, F. L. Almeida, F. G. R. Reyes CyTA - Journal of Food. 16:1, 679-691 (2018)

13. G. Cliff Lamb, N. DiLorenzo (eds.) Current and Future Reproductive Technologies and World Food Production (Springer 
Science+Business Media New York, 2014)

14. M-Z Nouri, K. J. Kroll, M. Webb, N. D. Denslow Gen Comp Endocrinol. 15(296), 113543 (2020).

15. H. Wang, U .Bussy, Y-W ChungDavidson, W. Li Journal of Chromatography B, 1009-1010, 1708, (2016)

16. B. Hirpessa, B.H. Ulusoy, and C. Hecer Journal of Food Quality 12, 5065386, (2020)

17. J. P. Nash, B. Davail-Cuisset, S. Bhattacharyya et al. Fish Physiology and Biochemistry, 22, 355-363, (2000)

18. Z. Long, L. Hong, J. Jie Chinese Journal of Analytical Chemistry, 35(7), 983987, (2007)

19. L. I. Peipei, Y. Zhongyong, S. Xiumei et al. J. Ocean Univ. China (Oceanic and Coastal Sea Research). 17 (5), 11711177 (2018)

20. A. Gravitte, T. Archibald, A. Cobble et al. Biomedical Chromatography, 35(3), 5065386 (2020)

21. Maximum Residue Limits (MRLs) and Risk Management Recommendations (RMRs) for residues of veterinary drugs in foods. Codex Alimentarius. CX/MRL-2,1-46 (2018)

22. Commission Regulation (EU) No. $37 / 2010$ on pharmacologically active substances and their classification regarding maximum residue limits in foodstuffs of animal origin. Oficial Journal of European Commissions, 37, 1-72 (2010)

23. China's Maximum Levels for Contaminants in Foods. GAIN Report Number: CH14058.Date: 12/11/2014. 19 p. (2014) 